\title{
Postgraduate Training Performance Evaluation Applying Weighting and Comprehensive Fuzzy Evaluation Methods
}

\author{
https://doi.org/10.3991/ijet.v16i01.18231 \\ Mei Wang, Zeng Zhang $\left.{ }^{(}\right)$, Mi Xu \\ Tianjin University, Tianjin, China \\ zhangzeng@tju.edu.cn
}

\begin{abstract}
Postgraduate training performance evaluation is an important part of higher education evaluation. In order to quantitatively evaluate the performance of postgraduate training combined with the needs of talent training in colleges and universities, a comprehensive evaluation system for postgraduate training performance is designed and proposed. The analytic hierarchy process and the entropy method are combined to determine the weights of seven input and output indicators, such as funding input, teacher source input, scientific research ability, and graduate output quality. The comprehensive fuzzy evaluation model is also applied. This paper tests the above models to evaluate the graduate training performance of 20 colleges at Tianjin University. It is found that the weight of student input and graduate output quality combined is $87.69 \%$, which makes them the key indicators to measure the performance of graduate training. Furthermore, it is concluded that the performance of the science college was significantly higher than that of the humanities college.
\end{abstract}

Keywords-Postgraduate training, performance evaluation, Combination weighting, fuzzy evaluation model

\section{Introduction}

The evaluation of the quality of higher education is an important part of higher education activities and is often based on a combination of judgment and quantitative criteria [1]. In China, graduate students are the top level of national education and the core element of the national innovation system. As a combination of education and science and technology, postgraduate education is responsible for the mission of supplying highly educated graduate students to the country's labor market. In 2018, the number of graduate students enrolled in China was about 858,000. A large number of graduate students makes an important contribution to the country's economic development. The contribution rate to China's economic growth is $3.1 \%$ [2], which is an important force to lead China's economic development. Based on the importance of education evaluation for higher education and the key role of graduate education, it is necessary to conduct an evaluation of graduate education efficiently. 
University performance evaluation has been included in the scope of policy leadership [3]. The evaluation of the training performance of colleges and universities, as the training units for graduate students and the main implementers of postgraduate education, is the focus of many academic studies. A large number of literature sources show that teaching conditions, infrastructure, and quality of postgraduate training are the main factors taken into account when assessing the performance of postgraduate training [4]. Among these, student satisfaction with the process of teaching can be appropriate for determining whether teaching quality is excellent or not, which are also helpful for university managers to judge performance [5]. In addition, accelerated genetic algorithm, projection pursuit classification model, principal component analysis, analytic hierarchy process, data envelopment method, fuzzy neural network, and input-output method $[6,7,8]$ are all important means of evaluating postgraduate training performance. However, due to different evaluation motivations and indicators, different evaluation methods often yield different results, thus, it cannot be used for reference directly.

Based on these considerations, this paper constructs a comprehensive performance evaluation system for graduate training according to the needs of talent cultivation in Chinese universities. To achieve it, this study combines the analytic hierarchy process (AHP) with the entropy method to determine the main factors affecting the performance of postgraduate training in colleges and universities. In order to test the proposed method, this research collects data from 20 colleges of Tianjin University, and the comprehensive fuzzy evaluation model is used to further quantitatively evaluate the performance of postgraduate training in Colleges and universities. The results show that the input of students and the quality of postgraduate training are important factors affecting the performance evaluation of the postgraduates, and the performance of the Science college is significantly higher than that of the Humanities College.

\section{Overview}

\subsection{Performance evaluation of university postgraduates' training}

The term performance has been around for a long time. Bernadin [9] believes that performance is the result of work and a record and consideration of organizational work. However, Campbell insists that performance differs from results and points out that performance should be perceived as a process behavior [10]. In this paper, the concept of performance is considered to cover both behavior and results. Therefore, performance evaluation should consider both input (behavior) and output (result). Meanwhile, evaluation is generally defined as the implementation and acceptance of the basic criteria to determine the value of things according to the selected criteria [11]. Therefore, the performance evaluation of postgraduate training refers to judging the value of postgraduate training results based on the two levels of behavior input and behavior output of postgraduate training. 


\subsection{Evaluation system}

Postgraduate training is a complex dynamic process, and its evaluation needs to take into account multiple factors. A large number of academic sources shows that some key input factors, such as human, financial, and facility resources, as well as some important outputs, including graduates, publications, and knowledge transfer (for example, patents and derivatives), are regarded as indicators of higher education activities $[12,13,14,15,16,17]$. Thus, based on the definition of performance, evaluation of postgraduate training and those classical literature, the paper proposes the performance evaluation index system for postgraduate training, as shown in Table 1.

The input in the evaluation system consists of three parts: student source input (the number and achievements of different types of postgraduate students), fund input (research funds and assistantship), and teacher input. The output consists of four parts: Scientific research ability (research project, high-level papers and the number of Key Research Centres or Laboratory Bases), course building ability (student satisfaction and number of classic courses), degree construction ability (number of academic degree authorization points, evaluation results), and graduate output quality (for instance, academic ability, employment competitiveness, and innovation ability).

Table 1. Performance evaluation system of graduate education

\begin{tabular}{|c|c|c|}
\hline Target-level indicators & First level indicators & Second level indicators \\
\hline \multirow{7}{*}{$\begin{array}{l}\text { Performance of Postgraduate } \\
\text { Training }\end{array}$} & \multirow{3}{*}{ Investment in Postgraduate Training } & Student Source input \\
\hline & & Funding input \\
\hline & & Teacher Source input \\
\hline & \multirow{4}{*}{ Output of Postgraduate Training } & Scientific Research Ability \\
\hline & & Course Building Ability \\
\hline & & Degree Building Ability \\
\hline & & Graduate Output Quality \\
\hline
\end{tabular}

\section{Methodology}

When evaluating a system with multiple rating indicators, a weighting factor is usually used to indicate the importance of different indicators for the evaluation results. The methods of weight determination include subjective weighting, objective weighting, and combined weighting. Subjective weighting (or empowerment) is conducted by experts, and it has certain reference significance. Among the common approaches, there are the Delphi and factor pair comparison methods. The traditional subjective empowerment often has the disadvantage of subjective preference. Nevertheless, the objective weighting method, which relies on actual data, can also have this shortcoming. The common objective weighting methods include principal component analysis, mean square error weighting, and entropy method. There are also shortcomings of the objective weighting method, which make it hard to reflect the importance of different indicators.

To address these shortcomings, this study applies the analytic hierarchy process and the entropy method to combine empowerment combined with the indicators sys- 
tem of graduate training performance evaluation and the applicability of various empowerment methods. On this basis, a comprehensive fuzzy evaluation model is constructed, and with its help, the objects are evaluated by the comprehensive scores obtained from calculations.

\subsection{Combination weighting with analytic hierarchy process and entropy methods}

Analytic Hierarchy Process (AHP) is a decision analysis method proposed by American Operations Research in the 1970s. The key to using AHP to empower is to construct a judgment matrix. From the first-level indicators of the system, a pairwise comparison matrix is constructed for the corresponding higher-level indicators. In this way, the n-dimensional judgment matrix is formed until the last layer. The importance of the correlation factors of the two pairs is the value in the matrix. This importance is assessed while referring to the nine-scale table proposed by Saaty [18]. This procedure is conducted by 12 experts, engaged in higher education administration, postgraduate teaching, scientific research, and employment. The experts construct the judgment matrix through three rounds of cross-scoring.

Entropy method19] is originally derived from thermodynamics, and it is a mathematical method to judge the discrete degree of the index by using the entropy value. If the value of entropy is large, the degree of dispersion is high. Thus, this particular index has a high contribution to the comprehensive evaluation and represents a large weight. When calculating the entropy value and corresponding weight of the evaluated object, the following steps are followed:

$$
x i j^{\prime}=\frac{x_{j-x_{\min }}}{x_{\max -x_{\min }}}
$$

Where, $i$ is the $i$-th evaluated object, and $j$ represents the $j$-th evaluation indicator. $x i j^{\prime}$ is the value of the $\mathrm{j}$-th indicator of the $\mathrm{i}$-th object to be evaluated.

Then, the proportion of the $\mathrm{j}$-th indicator in the $\mathrm{i}$-th evaluation object is calculated:

$$
\operatorname{Pij}=\mathrm{xij}^{\prime} / \sum_{i=1}^{m} x i j^{\prime}
$$

Where, $0 \leq$ Pij $\leq 1$ and $i=1,2, \ldots n, j=1,2, \ldots 7$

The next step is to calculate the entropy of the $\mathrm{j}$-th indicator:

$$
\mathrm{Ej}=-\mathrm{k} \sum_{i=1}^{m} p_{i j} \ln p_{i j}
$$

Where, $E j \geq 0$ and $k=1 / \ln (n)$ with $i=1,2, \ldots n, j=1,2, \ldots 7$.

Finally, the weight value of the $\mathrm{j}$-th indicator is:

$$
\mathrm{Wj}=(1-\mathrm{Ej}) / \sum_{i=1}^{m}(1-\mathrm{Ej})
$$




\subsection{Comprehensive fuzzy evaluation}

The comprehensive fuzzy evaluation method [20] is a mathematical method derived from the fuzzy set theory, and it is especially suitable for evaluation problems with multiple levels of influence factors that are difficult to quantify.

The performance of postgraduate training in colleges and universities is a complex system composed of various indicators and changes with the evaluation factors such as scientific research environment and teaching staff. The comprehensive fuzzy evaluation method is based on the fuzzy membership degree theory and is suitable for solving the above problems. When using this method to calculate the score of the evaluated object, it is necessary to construct an evaluation matrix, and based on this, the membership degree is obtained by the following formula:

$$
\mathrm{rab}=\left\{\begin{array}{c}
1, a=b \\
1-C \sum_{k=1}^{n}\left|x_{a k}-x_{b k}\right|, a \neq b
\end{array}\right.
$$

where, rab is a membership function, and $C$ is appropriately chosen so that $0<\mathrm{rab}$ $<1 \mathrm{rab}$ represents the membership grade score of the index a for the fuzzy subset of the grade $b$ relative to the evaluated unit. The final weight vector is $\mathrm{B}=\mathrm{W} 1 \times 30 * \mathrm{R} 30 \times$ $\mathrm{n}=\mathrm{B} 1 \times \mathrm{n}$.

\section{Model Application and Result Analysis}

\subsection{Preparation for survey}

This paper considers 20 colleges of Tianjin University as the research object to conduct an empirical study on the performance evaluation of postgraduates. The data used are from the official public data of Tianjin University's colleges from 2014 to 2018, the Employment Quality Report of Tianjin University and the statistical data of various centers. Data processing is completed by EXCEL, and the model analysis is carried out by MATLAB. The data are real and reliable, the analysis tools are scientific, and the research results are representative.

\subsection{Analysis of research results}

The subjective weights are determined by the analytic hierarchy process. From the first level of indicators, the corresponding indicators of the subordinate higher level are constructed into a pair comparison matrix until the last level, forming a 7dimensional judgment matrix. In order to ensure rationality, it is necessary to verify the random consistency ratio $(\mathrm{CR})$ of the judgment matrix: $C I=(\lambda \max -n) /(n-1)$. Then $\mathrm{CI}=0.0446$, and $\mathrm{CR}=\mathrm{CI} / \mathrm{RI}=0.0267<0.1$, therefore, the consistency test is passed, so the weights are reasonable. Then the objective weights of the seven indicators are determined according to the entropy method formula, and the weight vector is obtained using EXCEL for data processing. Finally, the followings are performed: the test of the consistency of subjective and objective weight results and Pearson con- 
sistency coefficient test. Since the $\mathrm{P}$ value is $0.02<0.05$, the results show that there is significance. Then through the multiplication synthesis, the final calculation of the weight results is conducted. The results are shown in Table 2.

Table 2. Weight calculation results

\begin{tabular}{|c|l|c|}
\hline First level indicators & \multicolumn{1}{|c|}{ Second level indicators } & Weight \\
\hline \multirow{4}{*}{ Investment in postgraduate training } & Student Source input & 0.5228 \\
\cline { 2 - 3 } & Funding input & 0.0384 \\
\cline { 2 - 3 } & Teacher Source input & 0.0061 \\
\hline \multirow{5}{*}{ Output of Postgraduate Training } & Scientific Research Ability & 0.0591 \\
\cline { 2 - 3 } & Course Building Ability & 0.0136 \\
\cline { 2 - 3 } & Degree Building Ability & 0.0059 \\
\cline { 2 - 3 } & Graduate Output Quality & 0.3541 \\
\hline
\end{tabular}

It can be seen from Table 2 that the results that most affect the performance evaluation of postgraduate training are the student input, graduate output quality, scientific research ability, funding input, curriculum construction ability, teacher investment, and degree building ability successively. Among them, the weight of student input and graduate output quality combined is $87.69 \%$, which is the key index to measure the performance of graduate training at Tianjin University.

Student input reflects the quality of student resources in colleges. Astin [21] has shown that students' educational background will affect students' educational activities during school. This study also proves that there is a close relationship between students' educational background and training performance. In addition, in a realm of postgraduate education, the quality of postgraduates has always been a key factor in evaluating the performance of postgraduate training in colleges and universities. It is also a necessary consideration to measure whether the training work of Tianjin University is qualified.

It is generally believed that the increased investments in human capital can improve the productivity of human capital itself; so, teachers are often seen as a key factor for the performance of graduate students [22]. However, the weight results show that the contribution of teacher investment to the evaluation of postgraduate training performance of Tianjin University is only $0.61 \%$. The metrics of teacher input in this paper are the ratio of students to teachers, the proportion of associate professors among the teachers, and the rationality of the teachers [23]. In the process of data collection, it is found that there is not much difference in the investment of teachers across 20 colleges. This may be the expert score, and the entropy calculation results finally show the main reason for the low weight score.

With regard to human capital investment, in academia, it is generally believed that inadequate funding is a key factor affecting the quality of postgraduate training. However, the weight results show that the contribution rate of funding to the evaluation of postgraduate training performance is only $3.84 \%$. This may indicate that at the present stage of the development of higher education, the dependence of postgraduate training on funding has weakened, and the role of funding in evaluating the performance of postgraduate training in colleges and universities has declined to a certain extent [24]. 
To further discuss the results of postgraduate training at Tianjin University, the paper constructed the evaluation matrix by using the comprehensive fuzzy evaluation model and the actual data on the object of study, which stipulates that the performance standards of graduate students in each college are five-level system, that is, $\mathrm{V}$ $=\{\mathrm{v} 1, \mathrm{v} 2, \mathrm{v} 3, \mathrm{v} 4, \mathrm{v} 5\}=\{\mathrm{A}, \mathrm{B}, \mathrm{C}, \mathrm{D}, \mathrm{E}\}=\{$ Excellent, Excellent, General, Qualified, Very Poor $\}$, and $\mathrm{V}=\{1,0.8,0.6,0.4,0.2\}$. After normalizing the index values, the comprehensive scores of each evaluated object are calculated according to the formu$\mathrm{la}$, in which the values of $\mathrm{a}=1,2, \ldots 7, \mathrm{~b}=0.2,0.4, \ldots 1$. Finally, the comprehensive scores and grades reflecting the training performance of graduate students at Tianjin University from 2014 to 2018 are obtained. The specific scores and rankings are shown in Figure 1.

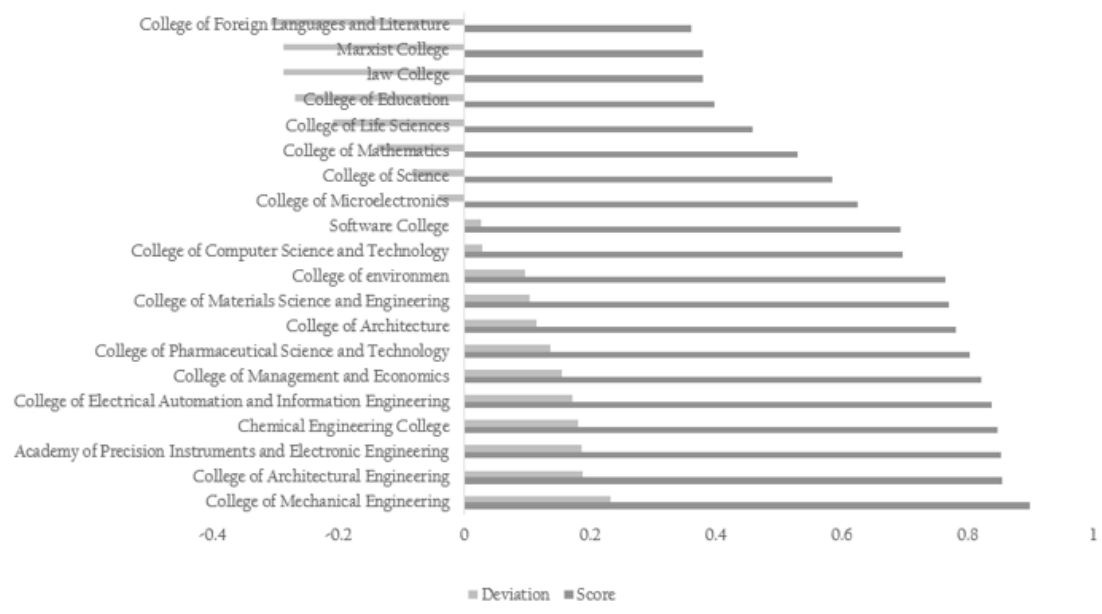

Fig. 1. Comprehensive score and ranking of postgraduate training performance

As the research results show, the average score of graduate training performance of Tianjin University is 0.67 , and overall, its training work is at a better level. In addition, there are obvious differences in the performance of postgraduate training in different colleges. The results of data analysis show that the postgraduate training performance of seven institutes (Mechanical Engineering College, Architectural Engineering College, Academy of Precision Instruments and Electronic Engineering, Chemical Engineering College, College of Electrical Automation and Information Engineering, School of Management and Economics, College of Pharmaceutical Science and Technology) is outstanding with ranking A. Among them, the comprehensive score of Mechanical Engineering College with the best performance is as high as 0.899 .

The results of postgraduate training in five colleges such as Architecture College, Material Science and Engineering College etc. are excellent, with an average score of about 0.72. Although the Software College and Microelectronics College both received grade B, there are some differences in their postgraduate training performance. According to the calculated deviation, the comprehensive score of training perfor- 
mance of Software College is $2.6 \%$ higher than the average level of Tianjin University, while that of Microelectronics College is $4.2 \%$ lower than the average level.

The results of postgraduate training in the colleges of science, mathematics, and life sciences are at a general level. The schools that have qualified the results of performance evaluation of graduate training are the Colleges of Education, Law, Marxist and Foreign Language and Literature; the average score of these colleges is only 0.38 . This result shows that the performance of postgraduate training in science or engineering Colleges is generally higher than that of Social Sciences Colleges, and the difference between the two reached 0.539 . Thus, there is a significant gap in the effectiveness of postgraduate training in various institutes, and the postgraduate training work of Social Sciences colleges at Tianjin University needs to be improved.

\section{Conclusion}

This paper evaluates the postgraduate training work in 20 colleges of Tianjin University from 2014 to 2018 by using the combination of the weighting method and comprehensive fuzzy evaluation model. This study is conducted to inform legislation development and reveal existing problems of postgraduate training work in colleges and universities. The following four main conclusions have been drawn:

Students' background is an important factor affecting postgraduate training performance. From 2014 to 2018, the proportion of students' background in the performance evaluation of postgraduate training in universities was as high as $52 \%$. This result shows that there is a close relationship between students' background and training performance. Students' background is becoming more and more important for evaluating the training of Postgraduates in Colleges and universities.

The output quality of postgraduates is an important consideration to measure the quality of postgraduate training. According to the evaluation index, the output quality of graduate students mainly inspects five aspects: research ability, innovation and entrepreneurship ability, practical ability, social work ability, and employment competitiveness. Its weight in the performance evaluation of graduate students' training in universities is nearly $35.4 \%$, which shows the importance of the output quality of graduate students.

The contribution rate of financial input to evaluating the performance of postgraduate training in Colleges and universities is low. According to the result of empowerment, the proportion of funds invested in the evaluation of graduate education in universities is only about $6 \%$. This result shows that the correlation between funds investment and training performance is small. Continuous improvement of funds investment may not make the performance of graduate education excellent. In the future, the work of graduate education in universities should reasonably evaluate the funding gap and increase funds use efficiency.

There are obvious differences in the performance of postgraduate training among different colleges. The quality of postgraduate training in science and engineering colleges is generally higher than that in social science colleges. According to the analysis results and the characteristics of the research object, Tianjin University be- 
longs to the Polytechnic School, which pays more attention to the science and engineering, and its source quality, graduate output quality, scientific research environment, and development level are also relatively dominant. In contrast, the development of humanities and social sciences is still insufficient, and the overall level of graduate training performance of the Academy of Social Sciences is low, so there is a phenomenon of unbalanced development of disciplines.

\section{Acknowledgement}

This research was supported by General Program of National Natural Science Foundation of China (71673124), General Topics of Education under the National Social Science Foundation of China (BDA140028).

\section{$7 \quad$ References}

[1] Marsh, H,W. (1997). Roche L,A., Making students' evaluations of teaching effectiveness effective: The critical issues of validity, bias and utility, American Psychologist, vol.52, no.11 pp.1187-1197. https://doi.org/10.1037/0003-066X.52.11.1187

[2] Liguo, L., Fan, D. (2019). The Impact of Postgraduate Education on Economic Growth in China: An Empirical Analysis on a Provincial Panel Data from 1996 to 2016, Tsinghua Journal of Education, vol.40, no.2, pp.56-65.

[3] Xiuchao, H. (2018). Exploration of Modern Higher Education Evaluation System with Chinese Characteristics to Improve the Quality of Talent Cultivation, China higher education research, no.10, pp.1-5.

[4] Beaxse, P, G., Patterson, D, M. (2005). Endogenous public expenditures on education, Journal of public Economic Theory, vol.7, no.4, pp.561-577. https://doi.org/10.1111/j.1467-9779.2005.00234.x

[5] Rowan, E.B., Jerome D.D. (2011). University performance evaluations: what are we really measuring? Studies in Higher Education, vol.7, no.37, pp.825-842. https://doi.org/10.1080/ 03075079.2010.549221

[6] Fernando, S., Jan J. C., Pablo, R, B. (2019). An integrated constrained fuzzy stochastic analytic hierarchy process method with application to the choice problem, Expert Systemswithh Applications, no.138, pp.112-128. https://doi.org/10.1016/j.eswa.2019.112822

[7] Emmanuel, T., Prasanta, K.D., Konstantinos, P., Ioannis, G. and Andreas, C, G. (2017). Evaluating higher education teaching performance using combined analytic hierarchy process and data envelopment analysis, Journal of the Operational Research Society, vol.68, no.4, pp.431-445. https://doi.org/10.1057/s41274-016-0165-4

[8] Dong, P., Dai F. (2009). Evaluation for teaching quality based on fuzzy neural network, Proceedings of the First International Workshop on Education Technology and Computer Science, no.1, pp.112-115. https://doi.org/10.1109/ETCS.2009.34

[9] Michael, A., Angela, B. (1998). Performance Management. London: The Cromwell Press.

[10] Campbell, J, P., McCloy, R, A., Oppler. (1993). S, H and Sager, C, E, A Theory of Performance. San Francisco, CA: Jossey-Bass.

[11] Jody, L, F., James, R, S., Blaine, R, W. (2011). Program evaluation: alternative approaches and practical guidelines. New York: Pearson Education.

[12] Tommaso, A. (2017). Management of Higher Education Institutions and the Evaluation of their Efficiency and Performance, Tertiary Education and Management, vol.23, no.3, pp.187-190. https://doi.org/10.1080/13583883.2017.1336250 
[13] Kristof, D,W. (2017). Laura, L, T.Efficiency in education: A review of literature and a way forward, Journal of the Operational Research Society, vol.68, no.4, pp.339-363. https://doi.org/10.1057/jors.2015.92

[14] Wmann, L. (2006). International Handbook on the Economics of Education, Economic Issues, vol.11, no.1, pp.96-100.

[15] Worthington, A, C., Higgs, H. (2011). Economies of scale and scope in Australian higher education, Higher Education, vol.61, no.4, pp.387-414. https://doi.org/10.1007/s10734010-9337-3

[16] Fiona, E., Alan, G. (2013). Factors influencing university research performance, Studies in Higher Education, vol.38, no.5, pp.774-792. https://doi.org/10.1080/03075079.2011.60181 1

[17] Kirsi, M,K., Tomi, J, K. (2012). Management by results and performance measurement in universities, Studies in Higher Education, vol.39, no.4, pp.574-589. https://doi.org/10.1080 103075079.2012.709497

[18] Saaty, T. (1996). The Analytic Hierarchy Process. Pittsburgh: RWS Publishing, 1996.

[19] Brian, B., Vincent, A. M. (1991). Maximum entropy in action. Clarendon Press Clarendon Press.

[20] Andre, J., Arnold, K and Hans, Z. (1986). Fuzzy sets theory and applications, 1986.

[21] Astin, A, W. (1970). The Methodology of Research on College Impact, Part Two, Sociology of Education, vol.43, no.4, pp.437-450. https://doi.org/10.2307/2111842

[22] Zhumadillayeva, A.; Orazbayev, B.; Santeyeva, S.; Dyussekeyev, K.; Li, R.Y.M.; Crabbe, M.J.C.; Yue, X.-G. (2020). Models for Oil Refinery Waste Management Using Determined and Fuzzy Conditions, Information, no.11, pp.299. https://doi.org/10.3390/info1106 $\underline{0299}$

[23] Shao, X.-F.; Gouliamos, K.; Luo, B.-F.; Hamori, S.; Satchell, S.; Yue, X.-G.; Qiu, J. (2020). Diversification and Desynchronicity: An Organizational Portfolio Perspective on Corporate Risk Reduction, Risks, no.8, pp.51. https://doi.org/10.3390/risks8020051

[24] Stefan Svetsky, Oliver Moravcik, Pavol Tanuska, Iveta Markechova. (2018). The Personalized Computer Support of Teaching, International Journal of Engineering Pedagogy (iJEP), vol.8, no.4, pp.56-70. https://doi.org/10.3991/ijep.v8i4.8149

\section{Authors}

Mei Wang has graduated from Tianjin University with a doctorate in management. She is an associate professor of higher education management and talent development in Tianjin University. She has published dozens of articles in core journals and hosted and participated in five national and provincial research projects. 18062111221@163.com

Zeng Zhang is a second-year master's degree in education economics and management student at the School of Education, Tianjin University. Her main research direction is the education quality assessment.

Mi Xu is a second-year master's degree in education economics and management student at the School of Education, Tianjin University. Her main research direction is the education quality assessment.2019212099@tju.edu.cn

Article submitted 2020-09-03. Resubmitted 2020-09-28. Final acceptance 2020-09-28. Final version published as submitted by the authors. 